\title{
GOVERNANÇA ADAPTATIVA DA ÁGUA E O PLANO DE ADAPTAÇÃO DA SABESP: PERMANÊNCIAS DE PRÁTICAS OU OPORTUNIDADES PARA TRANSFORMAÇÃO?'1
}

RESUMO: Este artigo trata da governança adaptativa da água na Macrometrópole Paulista. Iniciamos discutindo criticamente o conceito de governança adaptativa proposto pela abordagem da resiliência de Carl Folke, para, na sequência, a partir de uma revisão crítica da literatura, definir as principais características da governança adaptativa da água. Posteriormente, examinamos o Plano de Adaptação às Variações Climáticas para a Gestão de Recursos Hídricos na Regiāo Metropolitana de São Paulo, elaborado pela SABESP. A partir da confrontação entre os elementos de uma governança adaptativa da água e a análise do plano, concluímos que, embora haja alguns avanços nas açóes de planejamento do abastecimento público, a transição para uma governança adaptativa e resiliente da água se coloca como um importante desafio.

PALAVRAS-CHAVE: governança adaptativa; resiliência; água; Macrometrópole Paulista.

\footnotetext{
1 Artigo produzido no âmbito das pesquisas do Projeto Temático FAPESP 2015/03804-9 “Governança Ambiental na Macrometrópole Paulista Face à Variabilidade Climática".

2 Universidade Federal do ABC (UFABC), Santo André - SP - Brasil. Bióloga, mestre e doutoranda em Planejamento e Gestão do Território. ORCID: https://orcid.org/0000-0003-2647-6966. ruth.ramos@ufabc.edu.br.
} 


\section{ADAPTIVE WATER GOVERNANCE AND SABESP ADAPTATION PLAN: PERMANENCE OF PRACTICES OR OPPORTUNITIES FOR TRANSFORMATION?}

ABSTRACT: This paper addresses the water adaptive governance in the Sáo Paulo Macrometropolis. We start critically discussing the concept of adaptive governance from Carl Folke's framework of resilience thinking, in order to, after a critical literature review, define the main characteristics of adaptive water governance. Subsequently, we examine the Plan of Adaptation to Climate Variations for the Management of Water Resources in the São Paulo Metropolitan Region elaborated by SABESP. From the confrontation between the elements of adaptive water governance and the analysis of the plan, we conclude that, although there are some advances in water supply planning actions, the transition to adaptive and resilient water governance is a major challenge.

KEYWORDS: adaptive governance; resilience; water; São Paulo Macrometropolis.

\section{Introdução}

A relação entre clima e água é tão estreita que não é possível tratar dos impactos do aquecimento global sem examinar os efeitos negativos do aumento da temperatura do planeta nos sistemas hídricos e suas enormes consequências para a vida no planeta. Ainda que as projeçóes sejam incertas, de acordo com os cientistas climáticos, o panorama dos impactos das mudanças climáticas nos recursos hídricos é sombrio sobretudo para os países em desenvolvimento que estão localizados em regióes de clima tropical, como é o caso do Brasil (MARENGO, 2008). Eventos extremos, com significativo aumento ou diminuição de chuvas, devem se tornar cada vez mais intensos e frequentes no país, ocasionando, de um lado, maior frequência de enchentes e alagamentos com substancial aumento na vazão dos rios e, de outro, uma expressiva redução no volume e disponibilidade da água doce (MARENGO, 2008; MARENGO et al., 2020; NOBRE, 2011). A crise hídrica em São Paulo entre os anos de $2014 \mathrm{e}$ 2015 e os constantes problemas de enchentes e alagamentos com trágicas perdas de vidas humanas (TRAVASSOS et al., 2021) são paradigmáticos dos efeitos negativos da alteração dos regimes de chuva em regióes altamente urbanizadas.

Em face da alteração dos regimes de chuvas, da contínua poluição dos rios localizados na metrópole paulista e da crescente demanda por água, para enfrentar a diminuição do volume hídrico útil dos reservatórios geridos pela 
Companhia de Saneamento Básico do Estado de São Paulo (SABESP) — como no caso dos reservatório que formam o Sistema Cantareira (TORRES; CÔRTES; JACOBI, 2020) —, o governo estadual também atua na identificação de novas fontes hídricas que estão localizadas cada vez mais distantes das áreas urbanizadas da metrópole paulista. Segue-se uma estratégia que procura mananciais ainda náo integrados ao sistema de abastecimento metropolitano e que tenham disponibilidade hídrica suficiente para complementar e atender o alto consumo de água, principalmente para abastecer a metrópole expandida, como mostra o Plano de Aproveitamentos dos Recursos Hídricos da Macrometrópole Paulista, que a definiu enquanto uma regiáo de interesse para o aproveitamento hídrico (DAEE, 2013).

Mais recentemente, no final de 2020, a SABESP publicou o Plano de Adaptação às Variaçóes Climáticas na Gestão dos Recursos Hídricos para o Abastecimento da Região Metropolitana de São Paulo, no contexto do pós-crise hídrica. Ante uma previsão de precipitação pluviométrica abaixo da média para o verão de $2020-2021^{3}$, soma-se a atual crise sanitária causada pela pandemia de Covid-19, que tem exposto as persistentes desigualdades e injustiças no acesso e na distribuição de água potável, o que atinge a população mais vulnerável.

Um expressivo número de pesquisas tem se dedicado a refletir quais são as possibilidades para se aprimorar na governança da água, tornando-a mais apta para a lidar com os enormes desafios do mundo contemporâneo, tais como os momentos de crise, as incertezas climáticas e as mudanças inesperadas nos ecossistemas (CHAFFIN; GOSNELL; COSENS, 2014). Dentre elas estão os trabalhos de Carl Folke e demais pesquisadores associados ao Resilience Alliance ${ }^{4}$, que abordam o conceito de resiliência e governança adaptativa, reunindo estudos sobre a proteção de ecossistemas, as práticas da ação coletiva e os processos de decisão política para lidar com os problemas complexos relacionados ao uso e à gestão dos sistemas socioecológicos.

Com o propósito de contribuir com o debate sobre a governança da água na Macrometrópole Paulista (MMP), o presente artigo aborda especificamente a governança adaptativa da água. $\mathrm{O}$ trabalho inicia-se desenvolvendo um diálogo teórico-conceitual entre a concepção de resiliência e governança adaptativa proposta por Carl Folke $(2006,2016)$ e a visão crítica de John S. Dryzek

\footnotetext{
Como mostra a Nota de Alerta n ${ }^{\circ}$ 01/2021 (NOTA..., 2021).

4 https://www.resalliance.org/ Disponível em: https://www.resalliance.org/. Acesso em: 6 jan. 2022. De acordo com Carl Folke (2006, p. 260, tradução nossa), "Resilience Alliance é um consórcio de grupos e institutos de pesquisa de diversas disciplinas que colaboram para estudar a dinâmica dos sistemas socioecológicos. O objetivo da Resilience Alliance é estimular uma ciência interdisciplinar e integradora, utilizando resiliência como uma ferramenta abrangente".
} 
(2016) e Eric Swyngedouw $(2011,2019)$. Em seguida, com apoio na literatura que tem contribuído especificamente para o avanço do conceito da governança adaptativa, ao incorporar uma visão mais crítica da realidade social, indicamos as características da governança adaptativa da água. Na sequência, conduzimos uma análise exploratória da elaboração do Plano de Adaptação proposto pela SABESP (2020), para, a partir do contraponto entre os elementos de uma governança adaptativa da água e a análise do plano, indicar algumas implicaçóes para a governança adaptativa água na Macrometrópole Paulista.

\section{Governança adaptativa da água - um conceito em construção}

Nos últimos anos observa-se um crescente interesse nos estudos sobre governança adaptativa, existindo diferentes abordagens para o conceito. Karpouzoglou, Dewulf e Clark (2016), por meio de uma revisáo sistemática da literatura publicada no período de 2005 a 2014, verificaram que a maior parte dos estudos sobre governança adaptativa relaciona-se com a gestão dos recursos hídricos, o que na opinião dos autores pode indicar que esta é "uma área chave para adaptação às mudanças climáticas” (KARPOUZOGLOU; DEWUL; CLARK, 2016, p. 4, tradução nossa).

Neste artigo, abordamos a governança adaptativa da água enquanto um conceito que se origina no campo dos estudos sobre resiliência, gestão e governança de ecossistemas, que tem assumido uma posiçáo significativa na investigação científica. Compreendendo trabalhos que investigam a governança dos mais diversos sistemas socioecológicos, dentro os quais os sistemas hídricos, de modo geral, nesta perspectiva as pesquisas sobre governança adaptativa ocupam-se em estudar alternativas para que a sociedade possa enfrentar as contínuas dificuldades diante da necessidade de proporcionar e garantir, ao mesmo tempo, a proteção da biosfera e a manutenção de seus serviços ecossistêmicos (FOLKE, 2006, 2016; FOLKE et al., 2005; FOLKE et al., 2010). Sáo trabalhos que compreendem o conceito de resiliência oriundo de uma nova visão da Ecologia, nomeadamente a que compreende o funcionamento dos ecossistemas no contexto da perspectiva de dinâmicas náo lineares e da abordagem de sistemas adaptativos complexos como pilares do seu quadro explicativo (FOLKE, 2006, 2016).

Além de conceber que a estabilidade em um ecossistema é necessariamente transitória, considera-se que um sistema socioecológico é resiliente quando este possui capacidade de assimilar perturbaçóes, persistindo dentro do seu domínio de estabilidade sem modificar sua integridade estrutural e função (FOLKE, 
2006, 2016; FOLKE et al., 2010). Nesta abordagem, a governança adaptativa é interpretada como parte da resiliência e compreendida como aquela em que os processos decisórios se pautam em conhecimentos aprofundados sobre os ecossistemas, o que é amplamente difundido devido à existência de conexóes entre múltiplos atores em distintos níveis e escalas (FOLKE et al., 2005). Para que a governança adaptativa ocorra, há necessidade de instituiçôes mais flexíveis que permitirão ajustes constantes ${ }^{5}$, possibilitando que uma capacidade específica para enfrentar incertezas, complexidades e mudanças seja criada e desenvolvida (FOLKE et al., 2010; FOLKE, 2016).

Neste sentido, o enfoque da governança adaptativa examina a capacidade dos atuais arranjos institucionais e da rede de diferentes atores políticos, que tomam decisóes sobre a proteção e o uso dos ecossistemas em lidar com incertezas, mudanças e complexidades dos sistemas socioecológicos, visando a resiliência do sistema, nas quais a perda da biodiversidade e as mudanças climáticas se colocam como proeminentes (FOLKE et al., 2005). Portanto, as novas pesquisas de governança adaptativa representam esse movimento de busca por abordagens que compreendem que é preciso modificar a maneira como a sociedade tem compreendido e tomado suas decisôes sobre os diferentes ecossistemas — incluindo os sistemas hídricos - para inovar na governança ambiental (FOLKE et al., 2005; CHAFFIN; GOSNELL; COSENS, 2014; ARNOLD et al., 2017; CLEAVER; WHALEY, 2018).

Existem diversas críticas sobre a abordagem da resiliência e governança adaptativa, sobretudo devido à utilização de conceitos que são oriundos da Ecologia e da perspectiva dos sistemas complexos para analisar e explicar o mundo social (OLSSON et al., 2015). John S. Dryzek (2016) e Eric Swyngedouw $(2011,2019)$ são dois exemplos de autores de correntes teóricas distintas que fazem uma leitura crítica sobre a abordagem de resiliência e governança adaptativa proposta por Folke. A questão essencial para Dryzek (2016) é que, da maneira que o conceito de resiliência foi proposto, definindo que persistência das atuais estruturas é algo desejável, o processo de resiliência será incapaz de provocar as transformaçôes necessárias e almejadas para que a governança adaptativa tenha capacidade de lidar com os desafios contemporâneos das mudanças climáticas.

As críticas deste autor sobre o conceito de resiliência recaí sobre o fato de que, ao abordar a manutenção das instituiçóes sociais vigentes como solução, a

\footnotetext{
Flexibilidade e possibilidade de ajustes, comumente, são fatores considerados essenciais para governança adaptativa, pois, em tese, podem viabilizar que a sociedade tenha capacidade de gerenciar a dinâmica imprevisível dos ecossistemas.
} 
resiliência estará necessariamente atrelada a uma situação de dependência da trajetória (path dependence) e náo se constituirá essencialmente como uma proposta para transformação. Com base nesta leitura das dificuldades de se alterar processo sociais devido à trajetória dependente, o autor propóe o conceito de reflexividade ecossistêmica (ou reflexidade socioecossistêmica), no qual as estruturas institucionais, por meio de um processo de autocrítica, podem ter a oportunidade de reconhecer e aprender com suas falhas anteriores e tentar "ser algo diferente em vez de apenas fazer algo diferente” (DRYZEK, 2016, p. 942, tradução nossa). Em suma, para o autor, ao não englobar a necessidade de profundas transformaçóes sociais, a proposta da resiliência será insuficiente para que a governança adaptativa tenha capacidade de lidar com os dilemas e desafios contemporâneos, incluindo as mudanças climáticas.

Outro autor que coloca em xeque a literatura da resiliência é Erik Swyngedouw $(2011,2019)$, que trabalha no campo da geografia crítica e ocupa-se em evidenciar o que ele define como aspectos despolitizantes dos conceitos emergentes na literatura sobre mudanças climáticas (SWYNGEDOUW, 2011). O pesquisador vê resiliência como uma nova perspectiva que almeja construir uma relação mais simétrica entre o social e o natural (SWYNGEDOUW, 2019). Justamente pelo fato dessa literatura considerar que esta reconfiguração simétrica é factível e ignorar os conflitos que são constitutivos da sociedade e da sua interação com a natureza, a abordagem falha, segundo Swyngedouw (2019), porque acaba por encobrir as contradiçôes da ordem capitalista.

Ao discutir o caráter despolitizante do conceito de resiliência, o autor está realçando que observa as relaçóes socioecológicas como desiguais e conflitivas. Ele também assume em sua análise que uma visão dominante sobre mudanças climáticas necessariamente resultará em uma única escolha e consenso, algo que se constitui como inteiramente diferente de uma visão politizada das relaçóes socioecológicas (SWYNGEDOUW, 2011, 2019). Portanto, para Swyngedouw (2011), diferenças, discordâncias e conflitos são dimensóes políticas que não podem ser eliminadas quando se trata da interação entre sociedade e natureza.

Apesar de serem duas perspectivas distintas, fica claro, portanto, que ambos os autores observam de forma cética a agenda emergente de pesquisas sobre resiliência e governança adaptativa. É evidente que são diversas essas três perspectivas teóricas empregadas pelos autores — resiliência socioecológica de Carl Folke, path dependence de Dryzek e geografia crítica de Swyngedouw - e não é nosso objetivo, ao propor este diálogo, buscar uma conciliação teórica em si. Respondendo algumas das críticas que o pensamento da resiliência tem rece- 
bido, Folke destaca que, embora as questóes de poder e desigualdade não tenham sido estabelecidas como elementos centrais da abordagem (FOLKE, 2016), o avanço de pesquisas que adotam a perspectiva da resiliência para compreender a governança dos sistemas socioecológicos, ao incorporarem novas explicaçóes teóricas - por exemplo, estudando instituiçôes, redes sociais e transformação social —, tem contribuído para um melhor entendimento da dinâmica societal e para a evolução contínua da abordagem.

Tendo apresentando o conceito de governança adaptativa na perspectiva de Carl Folke e as principais críticas que a abordagem tem recebido, na próxima seção analisaremos, a partir da revisão da literatura, as principais característica de uma governança adaptativa da água.

\section{Principais características de uma governança adaptativa da água}

Para Pahl-Wostl (2009), a governança adaptativa da água é aquela em que o processo de decisão política — constituído por uma rede de atores estatais e não estatais em interaçôes multiníveis —- em resposta às mudanças esperadas ou em andamento, tem habilidade para alterar suas práticas e promover o aprendizado (PAHL-WOSTL, 2009; PAHL-WOSTL et al., 2012). Os trabalhos dos autores Chaffin, Gosnell e Cosens (2014), Arnold et al. (2017) e Cleaver e Whaley (2018) nos fornecem um interessante panorama sobre os limites que a abordagem de governança adaptativa tem apresentado.

Chaffin, Gosnell e Cosens (2014) chamam a atenção para que pesquisas de governança adaptativa estejam mais atentas às questóes de equidade e justiça socioambiental. Para estes autores, é preciso que pesquisadores tenham claro que estudos de governança adaptativa lidam, impreterivelmente, com a determinaçáo de um estado desejado para se tornar resiliente. Segundo eles:

[...] os pesquisadores devem dar atenção criteriosa aos papéis do poder, da equidade e da justiça (social e ambiental) no incentivo ou na inibição da governança adaptativa para o uso sustentável dos recursos. Quem determina o estado desejado a ser alcançado pela transformação para uma governança adaptativa e quais vozes não são ouvidas? (CHAFFIN; GOSNELL; COSENS, 2014, p. 10, tradução nossa).

Arnold et al. (2017), ao estudar a governança adaptativa da água por meio de revisão da literatura e notarem uma emblemática falta de atenção às questóes de justiça social, afirmam que esse é um fator bastante preocupante, especial- 
mente tendo em conta as críticas que a abordagem tem recebido ao não tratar das questóes de desigualdades e poder. Em suas palavras, "chamamos atenção para que haja uma preocupação mais sistemática e explícita à justiça social, às condições equitativas, ao ativismo social e de base comunitária, como características dos sistemas de governança adaptativa” (ARNOLD et al., 2017, p. 10, tradução nossa).

Por fim, Cleaver e Whaley (2018) também observaram que há uma importante preponderância de pesquisas sobre resiliência que náo consideram, em suas análises, questôes como conflito, aspectos de poder e justiça social. $\mathrm{Na}$ visão dos autores, "resiliência não é um processo necessariamente bom ou ruim visto que uma instituição resiliente pode perpetuar desigualdades" (CLEAVER; WHALEY, 2018, p. 7, tradução nossa). Para uma melhor análise, propóem que os pesquisadores utilizem "lentes para uma bricolagem crítica" (CLEAVER; WHALEY, 2018, p. 6, tradução nossa) construída a partir de uma comunicação entre a abordagem da governança adaptativa com o institucionalismo crítico, de modo a incluir uma dimensão mais criteriosa nas investigaçóes que se atente para estrutura, normas sociais e relaçóes de poder.

Uma comparação e síntese entre a proposta de Folke (FOLKE et al., 2005; FOLKE, 2016), e destes três trabalhos - Chaffin, Gosnell e Cosens (2014), Arnold et al. (2017) e Cleaver e Whaley (2018) — , de modo a visualizarmos os aspectos principais da governança adaptativa água, está apresentada no Quadro 1.

Quadro 1 - Aspectos principais da governança adaptativa da água

\begin{tabular}{|c|c|}
\hline $\begin{array}{l}\text { Folke et al., 2005; Folke, 2016; } \\
\text { Pahl-Wostl, } 2009\end{array}$ & Chaffin, Gosnell e Cosens (2014) \\
\hline $\begin{array}{l}\text { Necessita de um conhecimento aprofundado } \\
\text { da dinâmica dos ecossistemas. } \\
\text { Reconhece a dinâmica não linear dos ecos- } \\
\text { sistemas. } \\
\text { Processos de aprendizagem e de ajustes são } \\
\text { constantes. } \\
\text { O conhecimento deve pautar as práticas de } \\
\text { gestão adaptativa. } \\
\text { Depende da conexão de múltiplos atores em } \\
\text { redes. } \\
\text { Envolve amplo alcance e conexão de atores e } \\
\text { esferas decisórias, em múltiplas escalas e em } \\
\text { arranjos policêntricos e multiníveis. }\end{array}$ & $\begin{array}{l}\text { Depende de conexóes de múltiplos atores em } \\
\text { redes, para permitir uma ampla participação } \\
\text { e experimentação em todo o sistema de gover- } \\
\text { nança. } \\
\text { Deve buscar um melhor ajuste entre a escala } \\
\text { da governança e dos ecossistemas. } \\
\text { Precisa se atentar às questóes de poder, equi- } \\
\text { dade e justiça social e ambiental. }\end{array}$ \\
\hline
\end{tabular}




\begin{tabular}{|c|c|}
\hline Arnold et al. (2017) & Cleaver e Whaley (2018) \\
\hline $\begin{array}{l}\text { Tem o objetivo de construir ou melhorar a } \\
\text { resiliência do sistema socioecológico. } \\
\text { A estrutura deve ser policêntrica, modular, } \\
\text { conectada por meio de múltiplas redes de } \\
\text { stakeholder, com escalas aninhadas. } \\
\text { Depende de oportunidades robustas para par- } \\
\text { ticipação e deliberação. } \\
\text { É necessária maior atenção à justiça social, à } \\
\text { equidade e ao ativismo social e comunitário. }\end{array}$ & $\begin{array}{l}\text { Lida com múltiplos interesses em vários } \\
\text { níveis. } \\
\text { Envolve pluralidade de redes de atores. } \\
\text { Relaçóes de poder intermediam a conexão de } \\
\text { múltiplos atores. } \\
\text { Estruturas sociais, relaçóes de poder e normas } \\
\text { sociais moldam a governança adaptativa. } \\
\text { Atores poderosos sáo capazes de comandar os } \\
\text { debates, definir a agenda e legitimar os arran- } \\
\text { jos. }\end{array}$ \\
\hline \multicolumn{2}{|c|}{ Aspectos-chave de uma governança adaptativa da água } \\
\hline \multicolumn{2}{|c|}{$\begin{array}{l}\text { Enfatiza estratégias de gestão que se pautam nas características e em conhecimentos aprofun- } \\
\text { dados sobre os ecossistemas. } \\
\text { Tem o objetivo de construir, desenvolver e melhorar a resiliência em um sistema socioecoló- } \\
\text { gico. } \\
\text { Há processos de aprendizagem e de ajustes constates para lidar com o imprevisível e com as } \\
\text { mudanças. } \\
\text { Ocorre por meio de conexão entre atores diversos, em múltiplas escalas e níveis, reconhecendo } \\
\text { que as interaçóes são intermediadas por relaçóes de poder. } \\
\text { Escalas e níveis devem estar em estrutura aninhada, multinível e policêntrica. } \\
\text { Há oportunidades para participação da sociedade. Ocupa-se de identificar grupos que estão } \\
\text { marginalizados, promovendo participação ativa e justiça socioambiental. }\end{array}$} \\
\hline
\end{tabular}

Fonte: Elaboração própria.

\section{Estrutura da Governança da Água na MMP}

O Sistema Nacional de Gerenciamento de Recursos Hídricos (SNGRH) é formado por órgãos governamentais e colegiados compostos por representantes das três esferas governamentais, dos usuários dos recursos hídricos e de "entidades civis de recursos hídricos com atuação comprovada na bacia” (BRASIL, 1997). O território brasileiro foi dividido em 12 Regióes Hidrográficas ${ }^{6}$, cabendo a cada unidade federativa estabelecer os limites das bacias hidrográficas estaduais. A bacia hidrográfica é compreendida como a escala espacial adequada para implementação da política e de seus instrumentos e corresponde à área de atuação dos Comitês de Bacia Hidrográfica. A unidade de gestão no SNGRH é o comitê de

\footnotetext{
6 Para mais informações ver a página da Agência Nacional de Águas e Saneamento Básico. Disponível em: https:// www.gov.br/ana/pt-brhttps://www.ana.gov.br/aguas-no-brasil/panorama-das-aguas/copy_of_divisoes-hidrograficas. Acesso em: 14 out. 2021.
} 
bacia hidrográfica, compreendido como um colegiado deliberativo coordenado pelo governo nacional ou estadual, prevendo a participação dos entes federativos, dos usuários da água e de entidades civis.

O ente federal atua na execução da política, coordenando o SNGRH por meio da Agência Nacional das Águas e o Conselho Nacional de Recursos Hídricos. Também possui representação nos comitês de bacia quando estes gerenciam rios interestaduais e transfronteiriços. Porém, a maior parte destes comitês está sob a coordenação dos entes estaduais, que possuem o domínio sobre as águas superficiais e subterrâneas e as competências para gerir e planejar os recursos hídricos nos seus respectivos territórios. $\mathrm{O}$ ente municipal tem sua participação por meio de representação nos comitês de bacia e a sociedade civil tem sua atuação regulamentada desde que tenha atuação comprovada em recursos hídricos (BRASIL, 1997; GOMES; BARBIERI, 2004; ANA, 2019).

Distintos atores, visões e interesses compóem o SNGRH — no qual os comitês de bacia possuem um papel essencial — e há alta variação no estágio de desenvolvimento das capacidades institucional e operacional dos órgãos e colegiados que o compóe (ANA, 2019). O estado de São Paulo está dividido em sete regiôes hidrográficas e 22 Unidades Hidrográficas de Gerenciamento de Recursos Hídricos; seu Sistema Integrado de Gerenciamento de Recursos Hídricos (SIGRH) é formado por 21 comitês de bacia hidrográfica. Ademais, integram o SIGRH: o Conselho Estadual de Recursos Hídricos, o Comitê Coordenador do Plano Estadual de Recursos Hídricos e o Conselho de Orientação do Fundo Estadual de Recursos Hídricos. Além disso, São Paulo participa em quatro comitês interestaduais devido ao compartilhamento de bacias hidrográficas com os estados de Minas Gerais, Rio de Janeiro e Paraná (SÃO PAULO, 2017; RAMOS et al., no prelo).

Outros atores políticos estatais que tomam decisóes sobre os recursos hídricos também fazem parte do complexo arranjo da governança da água, tais como o Departamento de Águas e Energia Elétrica (DAEE), que tem o poder outorgante da água; a Empresa Metropolitana de Águas e Energia (EMAE), que é a operadora do sistema hidráulico para geração de energia e controle de cheia na RMSP e da Baixada Santista; a Companhia Ambiental do Estado de São Paulo (CETESB), que monitora a qualidade das águas superficiais e subterrâneas no estado de São Paulo e é o órgão ambiental responsável pelo controle e licenciamento ambiental; a SABESP, empresa mista responsável pelos serviços de água e esgoto; a Agência Reguladora de Serviços Públicos do Estado de São Paulo (ARSESP), que regula e controla os serviços de saneamento básico prestados pela SABESP; e, finalmente, a Secretaria Estadual de Infraestrutura e Meio 
Ambiente, que coordena esta estrutura político-institucional e é responsável por conduzir a política estadual ambiental e mais recentemente a política de infraestrutura $^{7}$ (RAMOS et al., 2020). Como se pode notar, trata-se de um arranjo de governança bastante complexo, não restrito à tomada de decisão que ocorre no âmbito do SIGRH.

Neste trabalho, compreendemos a Macrometrópole Paulista a partir da definição do Departamento de Águas e Energia Elétrica (DAEE): uma região com disponibilidade hídrica, em que as bacias hidrográficas são visualizadas de forma interligada, para o aproveitamento de seus recursos hídricos, visando garantir a disponibilidade de água para o abastecimento da metrópole paulista (PIRES DO RIO; DRUMMOND; RIBEIRO, 2016; RAMOS et al., no prelo). Cabe destacar que o sistema de abastecimento metropolitano é operado pela SABESP.

\section{Estudo de caso: o Plano de Adaptação da SABESP}

O Plano de adaptação às Variações Climáticas para a Gestão de Recursos Hídricos na RMSP foi lançado pela SABESP em 01/10/2020. Dois encontros no formato webinar foram promovidos pela empresa para participação do público interessado, anteriormente à publicação do plano (ver Figura 1).

Figura 1 - Convite do webinar promovido pela SABESP para elaboração do Plano de Adaptação ${ }^{8}$

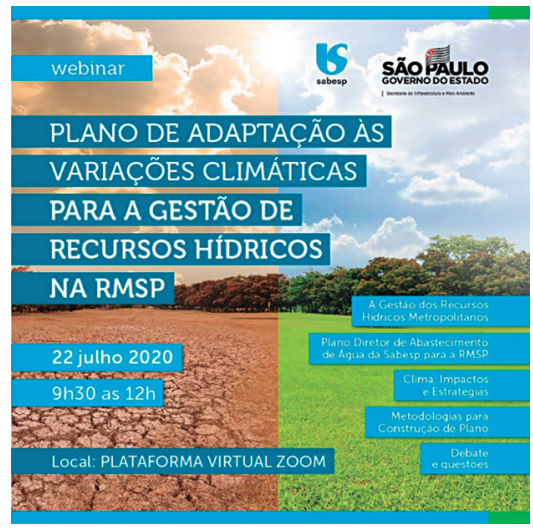

Fonte: Acervo próprio.

\footnotetext{
Para mais informações ver: https://www.infraestruturameioambiente.sp.gov.br/sima/organograma/. Acesso em: 6 jan. 2022.

8 Enviado pelo e-mail institucional da SABESP para a autora, que participou do referido evento.
} 
De acordo com a publicação, o plano foi elaborado para o aprimoramento da segurança hídrica e o fortalecimento da resiliência do Sistema Integrado de Abastecimento Metropolitano (SABESP, 2020). O documento de 65 páginas traz, em seus dois primeiros capítulos, um contexto mais geral sobre as mudanças climática e a influência do clima na disponibilidade da água. Na sequência, apresenta alguns dados mais específicos sobre o Sistema Integrado Metropolitano, descreve como ocorre a gestão dos recursos hídricos no Brasil e em São Paulo, para então apresentar o plano de adaptação para gestão da água na RMSP.

No plano, para a gestão resiliente dos recursos hídricos, foram definidas como medidas empregadas pela SABESP: (i) análise de vulnerabilidades; (ii) gestão de oferta; (iii) informação de previsão climática; (iv) flexibilidade dos sistemas hídricos; (v) participação; (vi) alocação negociada; (vii) planos de contingência e (viii) gestão de demanda e alinhamento institucional.

No Quadro 2 apresentamos uma síntese das medidas constantes no Plano de Adaptação da SABESP.

Quadro 2 - Síntese do Plano de Adaptação às variaçóes climáticas na gestão de recursos hídricos para o abastecimento da RMSP da SABESP.

\begin{tabular}{|l|l|}
\hline \multicolumn{1}{|c|}{$\begin{array}{c}\text { Medidas indicadas para gestáo } \\
\text { dos recursos hídricos }\end{array}$} & \multicolumn{1}{c|}{ Descrição } \\
\hline Análise de vulnerabilidades & $\begin{array}{l}\text { São ações estruturais e não estruturais dos sistemas } \\
\text { hídricos, considerando mudanças e variaçóes climáticas. }\end{array}$ \\
\hline Gestão de oferta & $\begin{array}{l}\text { Acontece por meio do aumento da capacidade de arma- } \\
\text { zenar água, da ampliação de transposiçóes de bacias e } \\
\text { da adoção de fontes alternativas e da otimizaçáo dos } \\
\text { sistemas de operação. }\end{array}$ \\
\hline Informação de previsão climática & $\begin{array}{l}\text { Representa um aprimoramento dos modelos de previsão } \\
\text { climática que alimentará a modelagem hidrológica, a } \\
\text { fim de avaliar os impactos nos sistemas ou na economia } \\
\text { em geral. }\end{array}$ \\
\hline Flexibilidade dos sistemas hídricos & $\begin{array}{l}\text { Capacidade de adaptação alcançada por meio de ações } \\
\text { estruturais e não estruturais, além de fornecer água tra- } \\
\text { tada por mais de uma fonte ou um sistema. }\end{array}$ \\
\hline Participação & $\begin{array}{l}\text { Trata-se do entendimento da alocação e do uso da água } \\
\text { de forma ampla, com todos os elementos inter-relacio- } \\
\text { nados, a fim de construir soluçóes socialmente justas e } \\
\text { tecnicamente sustentáveis. }\end{array}$ \\
\hline
\end{tabular}




\begin{tabular}{|l|l|}
\hline \multicolumn{1}{|c|}{$\begin{array}{c}\text { Medidas indicadas para gestáo } \\
\text { dos recursos hídricos }\end{array}$} & \multicolumn{1}{c|}{ Descriçáo } \\
\hline Alocação negociada & $\begin{array}{l}\text { Em situaçôes críticas, com ocorrência de eventos hidro- } \\
\text { lógicos extremos, propóem-se encontros das partes } \\
\text { interessadas, envolvendo gestores de recursos hídricos, } \\
\text { usuários, comitês de bacias e especialistas. }\end{array}$ \\
\hline Plano de contingência & $\begin{array}{l}\text { Elaboração associada ao planejamento de longo prazo } \\
\text { e frequentemente atualizada. Esses planos orientam } \\
\text { futuros momentos com eventos extremos, a fim de } \\
\text { mitigá-los. }\end{array}$ \\
\hline $\begin{array}{l}\text { Gestão da demanda e alinhamento } \\
\text { institucional }\end{array}$ & $\begin{array}{l}\text { São instrumentos essenciais para assegurar a resiliência } \\
\text { do sistema. Algumas das medidas contemplam cadastro } \\
\text { de usuários, mapeamentos dos maiores consumidores } \\
\text { por bacia, política tarifária, entre outros. }\end{array}$ \\
\hline
\end{tabular}

Fonte: Elaboração própria com base em SABESP (2020).

\section{Resultados e discussão}

A seguir, examinamos o Plano de Adaptação da SABESP, observando o processo de elaboração e as informaçóes disponibilizadas, contrastando esses dados com os principais aspectos de uma governança adaptativa. Busca-se, de forma exploratória, identificar elementos apresentados pelo plano que poderão estimular e possibilitar uma governança adaptativa da água na MMP. No Quadro 3 apresentamos uma síntese da avaliação do processo de elaboração e das informações disponibilizadas no Plano de Adaptação da SABESP.

Quadro 3 - Avaliação do processo de elaboração e das informaçôes disponibilizadas pelo Plano de Adaptação da SABESP.

\begin{tabular}{|c|c|l|}
\hline $\begin{array}{c}\text { Aspectos-chave para uma } \\
\text { governança adaptativa da água }\end{array}$ & Conclusão & \multicolumn{1}{c|}{ Justificativa } \\
\hline $\begin{array}{l}\text { As estratégias de gestão dos siste- } \\
\text { mas hídricos estão fundamentadas } \\
\text { no conhecimento aprofundado do } \\
\text { funcionamento dos ecossistemas, } \\
\text { incluindo informaçóes sobre a dinâ- } \\
\text { mica náo estável? }\end{array}$ & Não apresenta & $\begin{array}{l}\text { Embora o plano informe que a mode- } \\
\text { lagem climática foi incorporada pela } \\
\text { SABESP, o plano não disponibiliza } \\
\text { tais informaçóes. } \\
\text { Também não apresenta diagnóstico } \\
\text { atualizado sobre os sistemas hídricos, } \\
\text { considerando uma visão mais holísti- } \\
\text { ca da água. }\end{array}$ \\
\hline
\end{tabular}




\begin{tabular}{|c|c|c|}
\hline $\begin{array}{l}\text { Aspectos-chave para uma } \\
\text { governança adaptativa da água }\end{array}$ & Conclusão & Justificativa \\
\hline $\begin{array}{l}\text { Há o objetivo de construir e desen- } \\
\text { volver estruturas de gestão e de } \\
\text { governança da água mais resilientes? }\end{array}$ & Parcialmente & $\begin{array}{l}\text { O objetivo claramente é buscar a resi- } \\
\text { liência no sistema de abastecimento } \\
\text { (captação, tratamento e fornecimen- } \\
\text { to de água) para que não haja falhas. } \\
\text { Contudo, o plano não aborda a inte- } \\
\text { graçáo do sistema com a gestão dos } \\
\text { recursos hídricos e com a governança } \\
\text { da água. }\end{array}$ \\
\hline $\begin{array}{l}\text { Há processos de aprendizagem e de } \\
\text { ajustes constantes para lidar com o } \\
\text { imprevisível e com as mudanças? }\end{array}$ & Parcialmente & $\begin{array}{l}\text { Menciona que existe um monitora- } \\
\text { mento constante do sistema de abas- } \\
\text { tecimento, mas ele é exclusivamente } \\
\text { voltado para garantir a captação e o } \\
\text { abastecimento de água. }\end{array}$ \\
\hline $\begin{array}{l}\text { Há promoção da conexão entre ato- } \\
\text { res diversos, em múltiplas escalas e } \\
\text { níveis, reconhecendo que as intera- } \\
\text { çóes são intermediadas por relaçóes } \\
\text { de poder? }\end{array}$ & Não & $\begin{array}{l}\text { Embora o webinar tenha ocorrido } \\
\text { com a participação de distintos atores } \\
\text { estatais e não estatais, o foco do plano } \\
\text { de adaptação está nas açóes da pró- } \\
\text { pria SABESP, sem mencionar como } \\
\text { o plano poderá contribuir na gestão e } \\
\text { governança da água nem como o pla- } \\
\text { no de adaptaçáo se relacionará com as } \\
\text { estruturas formais existentes. }\end{array}$ \\
\hline $\begin{array}{l}\text { Há oportunidades para participação } \\
\text { da sociedade, ocupando-se em iden- } \\
\text { tificar grupos que estão marginaliza- } \\
\text { dos? }\end{array}$ & Não & $\begin{array}{l}\text { Embora tenha ocorrido dois webinars } \\
\text { para participaçáo da sociedade civil, } \\
\text { ela foi empregada especificamen- } \\
\text { te para a identificaçáo de ameaças e } \\
\text { soluçóes, no contexto de um plano já } \\
\text { em desenvolvimento. } \\
\text { Náo há menção das situaçóes de } \\
\text { desigualdades no acesso à água e de } \\
\text { medidas específicas para lidar com } \\
\text { esta situaçáo. }\end{array}$ \\
\hline
\end{tabular}

Fonte: Elaboração própria.

Sobre conhecimento aprofundado dos sistemas hídricos, a despeito do Plano de Adaptação da SABESP apresentar um longo texto sobre mudanças climáticas, ele não revela quais informaçôes específicas sobre os modelos de previsão climática foram empregadas para a modelagem hidrológica e que permitirão a "construçáo de cenários para a gestáo de riscos e o planejamento a longo prazo" 
(SABESP, 2020, p. 71). Adotar a modelagem climática no planejamento dos recursos hídricos certamente representa um importante avanço tanto para a gestão do abastecimento de água potável, quanto para governança da água na MMP.

Nesse sentido, destacamos que ter informaçôes atuais da dinâmica do clima na RMSP, baseado em modelagens climáticas é essencial, mas também é primordial que este conhecimento esteja disponível para a sociedade civil e demais atores da governança da água, de forma a pautar os processos decisórios. A disponibilização de informaçóes sobre a dinâmica dos ecossistemas para os diferentes atores políticos é uma dimensão essencial para que a governança adaptativa da água ocorra, uma vez que o conhecimento aprofundado pode contribuir para que seu arranjo institucional desenvolva habilidades específicas nos processos decisórios e ante situaçóes de crise (ARNOLD et al., 2017; PAHLWOSTL, 2009; FOLKE et al., 2005).

Nota-se que a SABESP justifica que elaborou o plano para ampliar a resiliência do sistema de abastecimento metropolitano. Assim, compreendemos que o conceito de resiliência empregado pela SABESP se circunscreveu na definição de estratégias para mitigar falhas na operação do sistema de abastecimento de água da RMSP, não abordando como se dará a integração de seu plano com o Sistema Integrado de Gerenciamento de Recursos Hídricos e o arranjo institucional da governança da água, aspecto fundamental na governança adaptativa. Cabe frisar que, embora a elaboração de um plano relacionado a atuação da SABESP no serviço de abastecimento de água potável seja relevante, certamente o alcance de um planejamento para a governança adaptativa da água precisa ser mais amplo, superando uma visão obsoleta e fragmentada dos sistemas hídricos e dos processos políticos. Para Folke et al. (2005) e Pahl-Wostl (2009, 2015), uma visão fracionada não somente dos ecossistemas, mas também das práticas políticas, tem resultado em falhas na governança, dado que medidas e planos que simplificam a complexidade dos problemas fatalmente têm se mostrado insuficientes para a governança adaptativa.

Por fim, destacamos ainda que o plano não aborda especificamente a questão da interação da SABESP e seu plano com os demais atores que compóe o arranjo institucional da governança da água. Também não tratou a desigualdade no acesso aos serviços de saneamento pelas populaçóes marginalizadas que moram em situação de precariedade habitacional e serão maiormente afetadas pelos efeitos negativos das mudanças climáticas. Como coloca a literatura crítica apresentada ao longo desse artigo (CHAFFIN; GOSNELL; COSENS, 2014; ARNOLD et al., 2017; CLEAVER; WHALEY, 2018), não há como se planejar a governança adaptativa da água sem lidar com as desigualdades sociais. Resiliência 
e governança adaptativa envolvem necessariamente a definição de um estado desejável a ser alcançado, que deve ir além do estudo da disponibilidade hídrica, visto que a água é um "recurso natural essencial à vida, ao desenvolvimento econômico e ao bem-estar social” (SÃO PAULO, 1991), conforme pressupóe a Política Estadual de Recursos Hídricos.

\section{Considerações finais}

Neste artigo, foi demonstrado que o conceito de governança adaptativa está em construção e que as críticas colocadas pela literatura especializada têm contribuído para o seu avanço, permitindo avaliaçóes mais abrangentes. Observamos que a governança adaptativa na perspectiva do pensamento da resiliência (FOLKE et al., 2005) se coloca como uma abordagem que requer não só uma melhor compreensão de como funcionam os sistemas ecológicos, mas também depende de uma visão sistêmica e original da própria interação entre os sistemas ecológico e social. Observa-se que uma pluralidade de conhecimento entre as ciências naturais e sociais é indispensável, harmonização que se faz necessária perante a necessidade de se abordar os atuais problemas complexos (OLSSON et al., 2015).

Com efeito, sob nosso entendimento, governança adaptativa diz respeito a compreender que, ao mesmo tempo em que a persistência dos sistemas sociais que mantém profundas e permanentes injustiças é absolutamente indesejável, a resiliência dos ecossistemas é desejável e urgente. Portanto, ao empregar a abordagem da governança adaptativa na perspectiva da resiliência, o pesquisador inevitavelmente precisa incluir em sua análise formas de retratar as situaçóes de injustiças, conflitos e assimetrias de poder, o que não elimina que esta abordagem envolverá também uma preocupação característica de visualizar que a complexa estrutura de governança toma decisôes políticas sobre os ecossistemas que intenciona proteger.

A revisão crítica realizada nos possibilitou elencar quais são as principais características de uma governança adaptativa da água. Para o estudo da governança da água na Macrometrópole Paulista, conduzimos uma análise exploratória do Plano de Adaptação para a gestão dos recursos hídricos da SABESP, concluindo que, embora nós compreendamos que o plano representa um avanço na forma de se planejar e decidir sobre o uso da água para o abastecimento público, o conjunto de informaçóes apresentadas pela SABESP apresenta-se modesto quando levamos em conta os principais aspectos que configuram uma governança adaptativa água. 
Diante disso, é preciso destacar que as açóes propostas pela concessionária para o Plano de Adaptação não indicam caminhos para transformação e, como vimos, a permanência ou mero ajuste das práticas existentes é algo divergente da proposta da governança adaptativa. Considerando a relevância da SABESP na governança da água na MMP, por sua posição de dominância no planejamento e execução dos serviços de saneamento na RMSP (RAMOS et al., 2020), compreendemos que a empresa estadual de saneamento, em teoria, teria condiçóes de promover uma prática mais inovadora na condução e definição de um plano de adaptação focado na gestão dos recursos hídricos.

Por outro lado, a transição para uma governança adaptativa da água na MMP não está somente relacionada à elaboração de diagnósticos e planos mais detalhados e complexos. Essencialmente, dependerá de uma vontade política e social para se inovar na governança ambiental, buscando a resiliência dos ecossistemas e a ruptura das situaçóes de desigualdades e injustiças (TORRES et al., 2020). Resta acompanhar quais outras oportunidades surgirão no âmbito da governança da água na MMP, inclusive diante de uma nova crise hídrica que se descortina devido à estiagem que afeta o território brasileiro ${ }^{9}$ no ano de 2021.

\section{REFERÊNCIAS}

AGÊNCIA NACIONAL DE ÁGUAS [ANA]. Conjuntura dos recursos hídricos no Brasil 2019: informe anual. Brasília: ANA, 2019. Disponível em: https:// www.snirh.gov.br/portal/centrais-de-conteudos/conjuntura-dos-recursos-hidricos/ conjuntura_informe_anual_2019-versao_web-0212-1.pdf. Acesso em: 05 mar. 2021.

ARNOLD, C. A.; GOSNEll, H.; BENSON, M. H.; CRAIG, R. K. Crossinterdisciplinary insights into adaptive governance and resilience. Ecology \& Society, Dedham, v. 22, n. 4, 2017. Disponível em: https://www.ecologyandsociety.org/vol22/ iss4/art14/. Acesso em: 05 mar. 2021.

BRASIL. Lei no 9.433, de 8 de janeiro de 1997. Institui a Política Nacional de Recursos Hídricos [...]. Diário Oficial da Uniáo, Brasília, DF, ano 135, n. 6, seção 1, p. 470, 9 jan. 1997. Disponível em: http://http://www.planalto.gov.br/ccivil_03/ LEIS/L9433.htm. Acesso em: 10 mar. 2021.

CHAFFIN, B. C.; GOSNELL, H.; COSENS, B. A. A decade of adaptive governance scholarship: synthesis and future directions. Ecology \& Society, Dedham, v. 19, n. 3,

9 Disponível em: https://jornal.usp.br/?p=432037. Acesso em: 20 out. 2021. 
2014. Disponível em: https://www.ecologyandsociety.org/vol19/iss3/art56/. Acesso em: 05 mar. 2021.

CLEAVER, F.; WHALEY, L. Understanding process, power, and meaning in adaptive governance: a critical institutional reading. Ecology \& Society, Dedham, v. 23, n. 2, 2018. Disponível em: https://www.ecologyandsociety.org/vol23/iss2/art49/. Acesso em: 05 mar. 2021.

COMPANHIA DE SANEAMENTO BÁSICO DO ESTADO DE SÃO PAULO [SABESP]. Estratégias Resilientes: um plano de adaptação às variaçôes climáticas na gestão dos recursos hídricos para o abastecimento da Região Metropolitana de São Paulo. 2. ed. São Paulo: SABESP, 2020. E-book. Disponível em: http://www.sabesp. com.br/estrategias_resilientes/. Acesso em: 28 mar. 2021.

DEPARTAMENTO DE ÁGUAS E ENERGIA ELÉTRICA [DAEE]. Plano Diretor de Aproveitamento de Recursos Hídricos para a Macrometrópole Paulista, no Estado de Sáo Paulo: Relatório Final. 2013. v.1. Elaborado pela Companhia Brasileira de Projetos e Empreendimentos (Cobrape). Disponível em: https://docs. google.com/uc?export=download\&confirm $=$ gKjf\&id=0B8iXiItOrl5aQ3FOc3psV0I5 b0k. Acesso em: 7 jan. 2022.

DRYZEK, J. S. Institutions for the Anthropocene: governance in a changing Earth System. British Journal of Political Science, Cambridge, v. 46, n. 4, p. 37-956, 2016.

FOLKE, C. Resilience (republished). Ecology \& Society, Dedham, v. 21, n. 4, 2016. Disponível em: https://www.ecologyandsociety.org/vol21/iss4/art44/. Acesso em: 05 mar. 2021.

FOLKE, C. Resilience: the emergence of a perspective for social-ecological systems analyses. Global Environmental Change, Oxford, v. 16, n. 3, p. 253-267, 2006.

FOLKE, C.; HAHN, T.; OLSSON, P.; NORBERG, J. Adaptive governance of social-ecological systems. Annual Review of Environment and Resources, Palo Alto, v. 30, p. 441-473, 2005.

FOLKE, C.; CARPENTER, S. R.; WALKER, B.; SCHEFFER, M.; CHAPIN, T.; ROCKSTRÖM, J. Resilience thinking: integrating resilience, adaptability and transformability, Ecology \& Society, Dedham, v. 15, n. 4, 2010. Disponível em: https:/www.ecologyandsociety.org/vol15/iss4/art20/. Acesso em: 05 mar. 2021.

GOMES, J. L.; BARBIERI, J.C. Gerenciamento de recursos hídricos no Brasil e no Estado de São Paulo: um novo modelo de política pública. Cadernos EBAPE.BR, Rio de Janeiro, v. 2, n. 3, p. 01-21, 2004. 
KARPOUZOGLOU, T.; DEWULF, A.; CLARK, J. Advancing adaptive governance of social-ecological systems through theoretical multiplicity, Environmental Science \& Policy, New York, v. 57, p. 1-9, 2016.

MARENGO, J.A. Água e mudanças climáticas. Estudos Avançados, São Paulo, v. 22, n. 63, p. 83-96, 2008.

MARENGO, J.A.; ALVES, L.M.; AMBRIZZI, T.; YOUNG, A.; BARREO, N.J.C.; RAMOS, A.M. Trends in extreme rainfall and hydrogeometeorological disasters in the Metropolitan Area of São Paulo: a review. Annals of the New York Academy of Science, New York, v. 1472, p. 5-20, 2020.

NOBRE, C. A. Vulnerabilidades das megacidades brasileiras às mudanças climáticas: regiâo metropolitana de São Paulo: Relatório final. São José do Campos, SP: INPE, 2011.

NOTA de alerta: A importância da reservação de água até março de 2021 para não pressionar a disponibilidade hídrica. Consórcio PCJ, Americana, 15 jan. 2021. Disponível em: https://agua.org.br/noticias/nota-de-alerta-a-importancia-da-reservacaode-agua-ate-marco-de-2021-para-nao-pressionar-a-disponibilidade-hidrica/. Acesso em: 28 mar. 2021.

OLSSON, L.; JERNECK, A.; THOREN, H.; PERSSON, J.; O’BYRNE, D. Why resilience is unappealing to social science: theoretical and empirical investigations of the scientific use of resilience. Science Advances, Washington, v. 1, n. 4, 2015. Disponível em: https://www.science.org/doi/10.1126/sciadv.1400217. Acesso em: 05 mar. 2021.

PAHL-WOSTL, C. Water governance in the face of global change: from understanding to transformation. Switzerland: Springer, 2015.

PAHL-WOSTL, C. A conceptual framework for analysing adaptive capacity and multi-level learning processes in resource governance regimes. Global Environmental Change, Oxford, v. 19, n. 3, p. 354-365, 2009.

PAHL-WOSTL, C.; LEBEL, L.; KNIEPER, C.; NIKITINA, E. From applying panaceas to mastering complexity: toward adaptive water governance in river basis. Environmental Science \& Policy, New York, v. 23, p. 24-34, 2012.

PIRES DO RIO, G.; DRUMMOND, H.R.; RIBEIRO, C.R. Água: urgência de uma agenda territorial. Ambiente \& Sociedade, Campinas, v. XIX, n. 4, p. 105-120, 2016.

RAMOS, R. F.; FREY, K.; BRAGA, D. R. G. C.; MODENEZI, G. Paradigmas da gestão integrada por bacia hidrográfica: contribuiçóes para o debate sobre governança 
da água na Macrometrópole Paulista. In: PASTERNAK, S.; BÓGUS, L.; JACOBI, P. R.; TORRES, P. H. C. (org.). Planejamento e governança da Macrometrópole Paulista: desafios de pesquisa interdisciplinar sobre complexidade territorial. No prelo.

RAMOS, R. F.; FREY, K.; CORREIA, A. M.; ANJOS, L. A. P.; LEONEL, A. L. Environmental Sanitation in the São Paulo Macrometropolis: perspectives for multilevel governance. Ambiente \& Sociedade, Campinas, v. 23, p. 1-21, 2020.

SÃO PAULO (Estado). Secretaria Estadual de Saneamento e Recursos Hídricos. Plano Estadual de Recursos Hídricos: PERH 2016-2019. São Paulo: Conselho Estadual de Recursos Hídricos/Comitê Coordenador do Plano Estadual de Recursos Hídricos. 2017. Disponível em: https://sigrh.sp.gov.br/public/uploads/ ckfinder/files/PERH\%202016-2019\%20INTERNET\%20225\%20dpi.pdf. Acesso em: 30 out. 2020.

SÁO PAULO (Estado). Lei no 7.663, de 30 de dezembro de 1991. Estabelece normas de orientação à Política Estadual de Recursos Hídricos bem como ao Sistema Integrado de Gerenciamento de Recursos Hídricos. Assembleia Legislativa do Estado de São Paulo, São Paulo, 1991. Disponível em: https://www.al.sp.gov.br/ repositorio/legislacao/lei/1991/lei-7663-30.12.1991.html. Acesso em: 10 mar. 2017.

SWYNGEDOUW, E. The Anthropo(Obs)cene. In: ANTIPODE EDITORIAL COLLECTIVE (ed.). Keywords in Radical Geopraphy: Antipode at 50. Oxford: Wiley Blackwell, 2019. Disponível em: https:/onlinelibrary.wiley.com/doi/ pdf/10.1002/9781119558071. Acesso em: 17 out. 2021.

SWYNGEDOUW, E. Whose environment? The end of nature, climate change and the process of post-politicization. Ambiente $\&$ Sociedade, Campinas, v. 14, n. 2, p. 69-87, 2011.

TORRES, P.H.C; CÔRTES, P.L.; JACOBI, P.R. Governing complexity and environmental justice: lessons from the water crisis in Metropolitan São Paulo (20132015). Desenvolvimento e Meio Ambiente, Curitiba, v. 53, p. 61-77, 2020.

TORRES, P.H.C.; LEONEL, A.L.; ARAÚJO, G.P.; JACOBI, P.R. Is the Brazilian National Climate Change Adaptation Plan addressing inequality? Climate and environmental justice in a Global South Perspective, Environmental Justice, New Rochelle, v. 13, n. 2, p. 42-46, 2020.

TRAVASSOS, L.; TORRES, P. H. C.; DI GIULIO, G.; JACOBI, P. R.; FREITAS, E. D.; SIQUEIRA, I. C.; AMBRIZZI, T. Why do extreme events still kill in the São Paulo Macrometropolis Region?: Chronicle of a death foretold in the global South. 
International Journal of Urban Sustainable Development, Oxfordshire, v. 13, n. 1, p. 1-16, 2021.

Recebido em: 30 de março de 2021

Aprovado em: 16 de setembro de 2021 